\title{
Article \\ Biomass Straw-Derived Porous Carbon Synthesized for Supercapacitor by Ball Milling
}

\author{
Bixia Jiang ${ }^{1}\left(\mathbb{D}\right.$, Lin Cao ${ }^{1, *}$, Qinghua Yuan ${ }^{2}$, Zhuwen $\mathrm{Ma}^{2}$, Zhenrui Huang ${ }^{2}$, Zhidan Lin ${ }^{1, *} \mathbb{C}$ and Peng Zhang $1, * \mathbb{C}$ \\ 1 Institute of Advanced Wear \& Corrosion Resistant and Functional Materials, Jinan University, \\ Guangzhou 510632, China; jiang0903@stu2020.jnu.edu.cn \\ 2 Key Laboratory of Crop Genetic Improvement of Guangdong Province/Guangdong Provincial Engineering \& \\ Technology Research Center for Tobacco Breeding and Comprehensive Utilization, Crops Research Institute, \\ Guangdong Academy of Agricultural Sciences, Guangzhou 510640, China; qinghuay@foxmail.com (Q.Y.); \\ conghuama@163.com (Z.M.); fjsi@163.com (Z.H.) \\ * Correspondence: lincao@stu2018.jnu.edu.cn (L.C.); linzd@jnu.edu.cn (Z.L.); tzhangpeng@jnu.edu.cn (P.Z.); \\ Tel.: +86-20-8522-0809 (L.C.); +86-20-8522-2151 (Z.L.); +86-20-8522-3562 (P.Z.)
}

check for updates

Citation: Jiang, B.; Cao, L.; Yuan, Q.; Ma, Z.; Huang, Z.; Lin, Z.; Zhang, P. Biomass Straw-Derived Porous

Carbon Synthesized for

Supercapacitor by Ball Milling.

Materials 2022, 15, 924. https://

doi.org/10.3390/ma15030924

Academic Editors: Meiqing Zeng and Zhongchen Lu

Received: 23 December 2021

Accepted: 15 January 2022

Published: 25 January 2022

Publisher's Note: MDPI stays neutral with regard to jurisdictional claims in published maps and institutional affiliations.

Copyright: (C) 2022 by the authors. Licensee MDPI, Basel, Switzerland. This article is an open access article distributed under the terms and conditions of the Creative Commons Attribution (CC BY) license (https:// creativecommons.org/licenses/by/ $4.0 /)$.

\begin{abstract}
A large amount of biomass straw waste is generated every year in the world, which can cause serious environmental pollution and resource waste if disposed of improperly. At present, biomass-derived porous carbon materials prepared from biomass waste as a carbon source have garnered attention due to their renewability, huge reserves, low cost, and environmental benevolence. In this work, high-performance carbon materials were prepared via a one-step carbonization-activation method and ball milling, with waste tobacco straw as precursor and nano- $\mathrm{ZnO}$ as template and activator. The specific surface area and porous structure of biomass-derived carbon could be controlled by carbonization temperature, which is closely related to the electrochemical performances of the carbon material. It was found that, when the carbonization temperature was $800{ }^{\circ} \mathrm{C}$, the biochar possesses maximum specific surface area $\left(1293.2 \mathrm{~m}^{2} \cdot \mathrm{g}^{-1}\right)$ and exhibits high capacitance of $220.7 \mathrm{~F} \cdot \mathrm{g}^{-1}$, at $1 \mathrm{~A} \cdot \mathrm{g}^{-1}$ current density in a three-electrode configuration with $6 \mathrm{M} \mathrm{KOH}$ aqueous solution. The capacitance retention maintained about $94.83 \%$ at $5 \mathrm{~A} \cdot \mathrm{g}^{-1}$ after 3000 cycles. This work proves the porous biochar derived from tobacco straws has a great potential prospect in the field of supercapacitors.
\end{abstract}

Keywords: porous carbon materials; supercapacitor; tobacco straws; biochar

\section{Introduction}

With the surge of population, the booming of agriculture has led to a rapid increase of agricultural waste. China, as the largest agricultural country in the world, produces a large amount of agricultural and forestry biomass waste every year, and most of the biomass waste is mainly sourced from crop straw, forest straw and organic waste [1-3]. According to the China Statistical Yearbook 2019, China had produced about $8.65 \times 10^{9}$ tons of straw in 2019 [4], which occupied a large part of the total biomass resources in China, and this proportion will continue to rise in the future. However, only a small amount of straw waste was being recycled, used as feed and fertilizer materials [5,6]. Most of the straw was still disposed of in the traditional way: burning or direct disposal. The decay of straw waste would absorb a large amount of nitrogen, phosphorus and potassium and lead to a decrease in soil fertility, while open burning would also produce a large amount of carbon dioxide and other pollutants, leading to serious environmental pollution, and causing waste of renewable resources due to its renewability [7-9]. Therefore, promoting the comprehensive utilization of straw resources and transforming into high added value materials are of great practical significance for environmental protection, resource conservation and economic development. 
In recent years, the productions of biomass carbon materials from agricultural wastes have become a research hotspot in energy storage. Biomass is an ideal precursor for preparing various types of carbon materials because of its abundant reserves, convenient transportation and sustainable development $[10,11]$. There have been many reports on the utility of biological waste to prepare biochar, such as banana peels [12], corn cobs [13], baobab husks [14], pomegranate peels [15], and wheat straw [16] and so on. These biochar materials are widely used in various fields because of their low cost, wide sources, considerable economic value and diversified morphology, such as soil improvers [17], wastewater treatment adsorbents [18], catalysts [19], etc. Specifically, the biochar as electrode materials for supercapacitors would be a promising application, which suffers from the competitive relationship between the abundant electrochemically active sites and the fast ion transfer channel from biochar. However, it still faces tremendous challenges in simultaneously designing and preparing biomass-derived carbons with excellent capacitive and rate performance.

Regarding to the high performance of supercapacitors, ideal carbon materials should own high specific surface area, hierarchical porous structure (combination of mesoporous and microspores), and heteroatom doping [20-22]. The physicochemical properties of biomass-derived carbon materials play a key role in the electrochemical performance of supercapacitors, which all depend on the preparation process of high-performance biomass carbon materials [23]. Therefore, it is important to develop an efficient and simple method to prepare biochar electrode materials with porous structures. Currently, chemical activation, such as $\mathrm{KOH}, \mathrm{ZnCl}_{2}$, or $\mathrm{H}_{3} \mathrm{PO}_{4}$, is commonly used to optimize the porous structure of carbon. Sun [24] prepared activated carbon by hydrothermal processing and chemical activation using hemp stems as the carbon source and $\mathrm{KOH}$ as the activator, with a specific surface area of $2879 \mathrm{~m}^{2} \cdot \mathrm{g}^{-1}$ and specific capacitance of $160 \mathrm{~F} \cdot \mathrm{g}^{-1}$. Wu [25] prepared bioactive carbon with $\mathrm{KOH}$ and $\mathrm{HNO}_{3}$ activation by using almond shell as raw material, with specific surface area of 1363 and $327.7 \mathrm{~m}^{2} \cdot \mathrm{g}^{-1}$ and specific capacitance $\left(1 \mathrm{~A} \cdot \mathrm{g}^{-1}\right)$ of 272.3 and $286.1 \mathrm{~F} \cdot \mathrm{g}^{-1}$, respectively. However, despite that the activation would help to produce a high specific surface area of biochar materials during the preparation process, the over-corrosive effect of these activators would produce larger pores, which is harmful for ion transport. In addition, these activators are usually corrosive to instruments and produce acidic or alkaline effluents [26-28]. Accordingly, many new methods have been developed to design the pore structure of carbon materials, among variety methods; template carbonization could control the morphology and pores structure of carbon materials efficiently [29-32]. Jian [33] prepared a mesoporous carbon material with nano-ZnO as a template using egg white as carbon source, with specific capacitance of $205 \mathrm{~F} \cdot \mathrm{g}^{-1}$ (current density of $0.5 \mathrm{~A} \cdot \mathrm{g}^{-1}$ ) and excellent cycling performance (97\% retention after 3000 cycles). $\mathrm{Xu}$ [34] prepared a bio-porous carbon material by using rhombus shell as carbon precursor, nano- $\mathrm{ZnO}$ as template and $\mathrm{KOH}$ as activator, with a high electrochemical property with specific surface area up to $1537 \mathrm{~m}^{2} \cdot \mathrm{g}^{-1}$ and specific capacitance of $128 \mathrm{~F} \cdot \mathrm{g}^{-1}\left(5 \mathrm{mV} \cdot \mathrm{s}^{-1}\right)$.

Nano-ZnO has been used as a template material because of several unique characteristics. On the one hand, it has been shown that nano- $\mathrm{ZnO}$ could be used both as a hard template to produce mesoporous and also as an activator to prepare hierarchical porous carbon; therefore, nano- $\mathrm{ZnO}$ is a promising dual-role additive to prepare porous carbon $[35,36]$. On the other hand, $\mathrm{ZnO}$ could be easily removed by using acids or alkaline for its essentially amphoteric properties.

The aim of this work is to explore a simple and efficient carbonization-activation method to prepare straw-derived carbon and develop the economic value of waste tobacco straws. In this study, tobacco straw-derived carbon was prepared by one-step carbonization activation method with ball milling method, with nano- $\mathrm{ZnO}$ as the template and activator, and tobacco straws as carbon precursor. Furthermore, the carbonization temperature has a significant influence on the morphology, specific surface area and electrochemical performance. Therefore, the structural properties of the carbon materials obtained at 
different carbonization temperature were carried out in this paper. This study can provide a new way to prepare electrode materials by carbonization of biomass.

\section{Experimental Section}

\subsection{Materials}

Tobacco straws were collected from Crops Research Institute, Guangdong Academy of Agricultural Sciences (Guangzhou, China), which were first cleaned with deionized water and absolute ethanol and then dried at $105^{\circ} \mathrm{C}$ overnight. The dried straws were crushed into powders and sieved by a 200-mesh. Nano-ZnO (diameter: $30 \pm 10 \mathrm{~nm}$ ) was provided by Shanghai Aladdin Biochemical Technology Co., Ltd. (Shanghai, China).

\subsection{Synthesis of Porous Carbon Materials}

Tobacco straw-derived carbon materials were prepared by using the dual effects of nano- $\mathrm{ZnO}$ with one-step carbonization and activation method. Typically, tobacco straw powder and nano-ZnO were mixed in weight ratio of 1:1 by ball milling (QM-3SP2, Nanjing, China) for $2 \mathrm{~h}$ at $350 \mathrm{rpm}$ [35]. Then the mixture was transferred into nickel crucible and placed in tubular furnace for carbonization at $700-900{ }^{\circ} \mathrm{C}\left(5^{\circ} \mathrm{C} \cdot \mathrm{min}^{-1}\right)$ for $2 \mathrm{~h}$ under $\mathrm{N}_{2}$ atmosphere. The products were washed with excess $1 \mathrm{M} \mathrm{HCl}$ and deionized water, then dried in the vacuum at $80{ }^{\circ} \mathrm{C}$ overnight. According to the different carbonization temperature of tobacco straw powder and nano- $\mathrm{ZnO}$ mixture, the obtained carbon samples were named as TCZn-X, where $X$ represents the carbonization temperature. Based on our previous research [37], for comparison, the carbon sample prepared from tobacco straw at $800{ }^{\circ} \mathrm{C}\left(5^{\circ} \mathrm{C} \cdot \mathrm{min}^{-1}\right)$ under $\mathrm{N}_{2}$ for $2 \mathrm{~h}$ without nano- $\mathrm{ZnO}$ was noted as TC-800.

\subsection{Materials Characterization}

The morphologies and microstructures of the carbon materials were observed by field emission scanning electron microscope (FESEM, Zeiss, ULTRATM 55, Jena, Germany) and field-emission transmission (TEM, JEOL, JEM-2100F, Tokyo, Japan). The crystallographic phases and composition analysis were measured using X-ray diffraction (XRD, Rigaku Ultima IV instrument, Tokyo, Japan), and Raman spectra were recorded by Raman spectrometer at wavelength of $633 \mathrm{~nm}$ (LR-3, Varian, Palo Alto, CA, USA).

Furthermore, the pore size distributions and specific surface areas of the carbon materials were measured by a BSD-PS2 (Beijing, China). The surface area porosity analyzer calculated via the Brunauer-Emmett-Teller (BET) method. The nitrogen-adsorption/desorption was performed on the carbon samples at $77.3 \mathrm{~K}$ after they had been degassed at $573 \mathrm{~K}$ for $3 \mathrm{~h}$.

\subsection{Electrochemical Characterization}

All the electrochemical properties of the carbon samples were carried out on a $\mathrm{CHI}$ $760 \mathrm{E}$ workstation (CH Instruments, Austin, TX, USA) by a typical three-electrode configuration in a $6 \mathrm{M} \mathrm{KOH}$ solution at room temperature. A platinum sheet $(10 \mathrm{~mm} \times 10 \mathrm{~mm})$ and a saturated calomel electrode were used as counter electrode and reference electrode (SCE), respectively. For the preparation of working electrodes, sample powders, polytetrafluorethylene (PTFE) and acetylene black were thoroughly mixed at a mass ratio of 8:1:1, and then coated onto the nickel foam $(10 \mathrm{~mm} \times 10 \mathrm{~mm})$ and dried at $80{ }^{\circ} \mathrm{C}$ overnight. Afterwards, the working electrodes were pressed at a pressure of $10 \mathrm{MPa}$ and used for further studies.

The electrochemical test in this experiment mainly includes cyclic voltammetry (CV), galvanostatic charge-discharge (GCD), and electrochemical impedance spectroscopy (EIS). For the three-electrode configuration, the specific capacitances were calculated from galvanostatic charge-discharge curve as follows:

$$
C_{s}=\frac{I \Delta t}{m \Delta V}
$$


where $C_{S}\left(\mathrm{~F} \cdot \mathrm{g}^{-1}\right)$ is the specific capacitances of the working electrode, $I(\mathrm{~A})$ is the current, $\Delta t$ is the discharge time, $m(\mathrm{~g})$ is the weight of the active materials on the working electrode, $\Delta V(\mathrm{~V})$ is the range of the potential [38].

\section{Results and Discussion}

\subsection{Materials Characterization}

Based on our previous work [37], compared with carbon materials directly prepared at different pyrolysis temperatures, the biochar (TC-800) obtained directly by pyrolysis at $800{ }^{\circ} \mathrm{C}$ had the better performance, so TC-800 was used as the control group.

The surface morphologies and porous properties of TC-800, TCZn-700, TCZn-800 and TCZn-900 were analyzed based on SEM (Figure 1) and TEM (Figure 2). As shown in Figure $1 \mathrm{a}, \mathrm{b}$, the surface of TC-800 was relatively smooth and covered by large-size lumps, while the sample was directly pyrolyzed at $800{ }^{\circ} \mathrm{C}$ without nano-ZnO. In contrast, when the nano- $\mathrm{ZnO}$ was introduced into the tobacco carbon sample, the surface of the TCZn- $\mathrm{X}$ samples showed a much rougher surface and looser structure with abundant interconnected pores as shown in Figure 1c-h. Meanwhile, the temperature was a key factor to affect the surface morphology of TCZn-X samples. The convex part of TCZn-700's edge is smooth with almost no pores, while the concave part is rough with few vesicles (Figure 1c,d), which may be due to insufficient carbonization temperature and incomplete carbonization. As shown in Figure 1e,f, there are a larger number of pores of smaller diameters and various depths of TCZn-800, which makes the roughness of TCZn-800 larger than that of TCZn-700. This is consistent with its TEM images (Figure 2a,b), and the high-resolution TEM further shows the abundant microspores and mesoporous of the carbon skeleton of TCZn- 800 . The surface roughness of TCZn-900 is similar to that of TCZn-800. However, the pore size of TCZn-900 is larger and looser, and the pore distribution is uneven. These results may be attributed to the high carbonization temperature led to excessive carbonization, pore collapse and deformation. The $S_{\mathrm{BET}}$ and $S_{\text {micro }}$ of the samples at different temperatures are different, mainly due to the weak electronic conductivity and small specific surface area of the samples annealed at low temperature (TCZn-700); the samples annealed at high temperature (TCZn-900) have a high degree of graphitization and crystal Due to the high degree of density, some pores are blocked, and the specific surface area is limited. The porous structure of the TCZn-X samples could be attributed to the activation and template effect of nano- $\mathrm{ZnO}$ [30]. In the preparation of carbon materials, nano- $\mathrm{ZnO}$ was used as hard template and activating agent. The site-occupying effect of nano- $\mathrm{ZnO}$ was similar to silica, mainly produced mesoporous. Also, nano-ZnO can etch some carbon atoms at high temperature to create micropores, as well as enlarge the meso/macropores according to the following reaction [36]:

$$
\mathrm{ZnO}+\mathrm{C}=\mathrm{Zn}+\mathrm{CO}
$$

The porous structure was found to be essential for high surface area in electrode material, which could facilitate constructing a better electrolyte diffusion and ion storage container for supercapacitors [39].

The specific surface area and porous structure of the samples were calculated by $\mathrm{N}_{2}$ adsorption/desorption isotherms (Figure 3a,b). Obviously, all the samples exhibit typically combined type I and IV isotherms. The IV-type hysteresis loops as observed in isotherms of all the TCZn-X samples, suggesting the existence of abundant mesopores [40]. The above results are consistent with TEM analysis. Moreover, the specific areas of the samples were calculated by Brunauer-Emmett-Teller (BET) method and Barret-Joyner-Halenda (BJH) model. As shown in Table 1, the addition of nano- $\mathrm{ZnO}$ did have a significant effect on the specific surface area (SSA), the SSA of TC-800 without nano-ZnO is only $569.4 \mathrm{~m}^{2} \cdot \mathrm{g}^{-1}$, while the SSA is effectively increased with nano-ZnO as template and activator, especially the SSA of TCZn-800 is high to $1293.2 \mathrm{~m}^{2} \cdot \mathrm{g}^{-1}$, which was beneficial to improve the SSA of carbon materials as supercapacitor electrodes. These results could be attributed to the dual role of nano- $\mathrm{ZnO}$ during the activation process [41]. The mesoporous hierarchical 
structure in the TCZn-X samples contributed to enhancing both storage and transport of electrolyte ions.
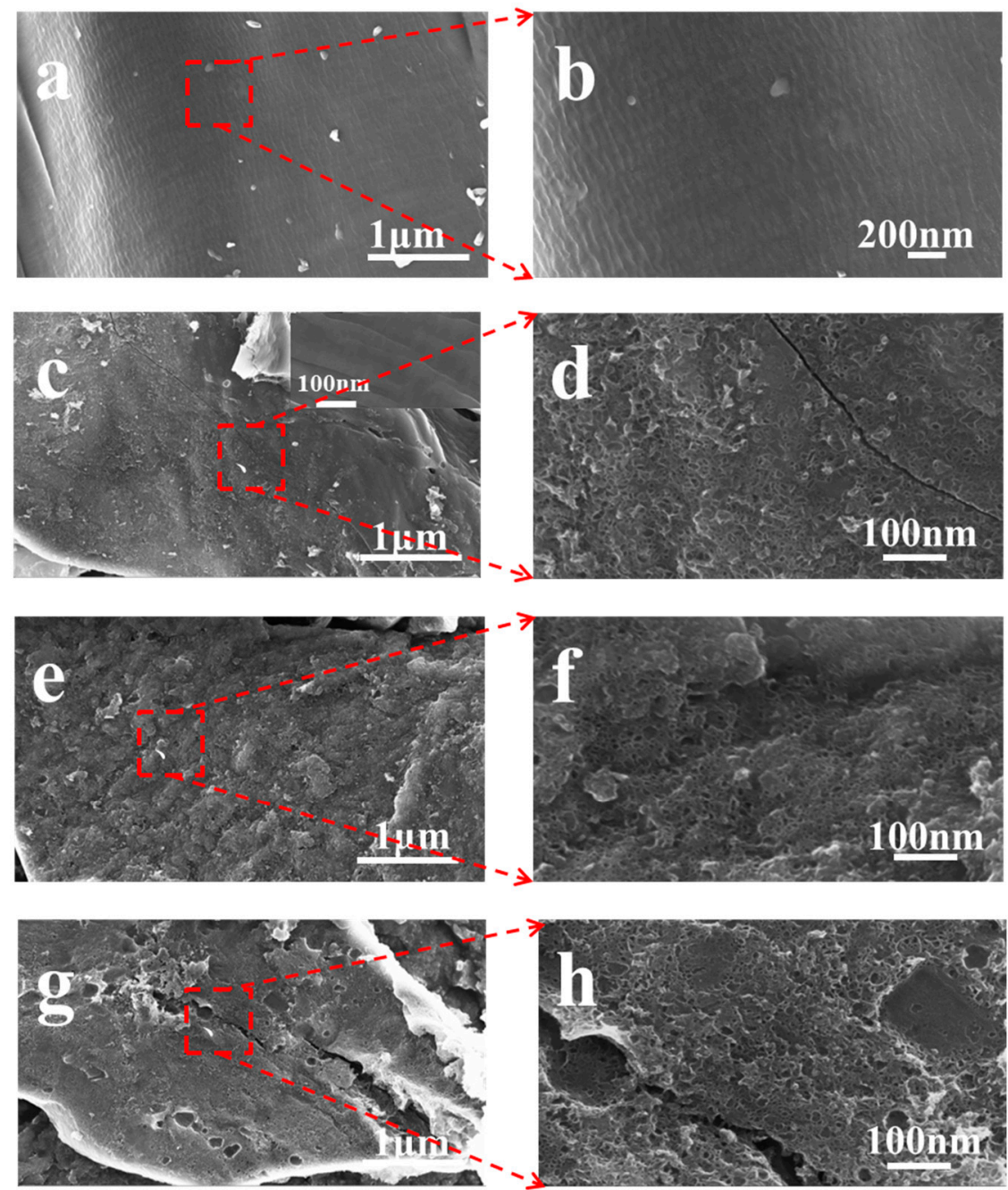

Figure 1. SEM images of (a,b) TC-800; (c,d) TCZn-700; (e,f) TCZn-800; (g,h) TCZn-900.
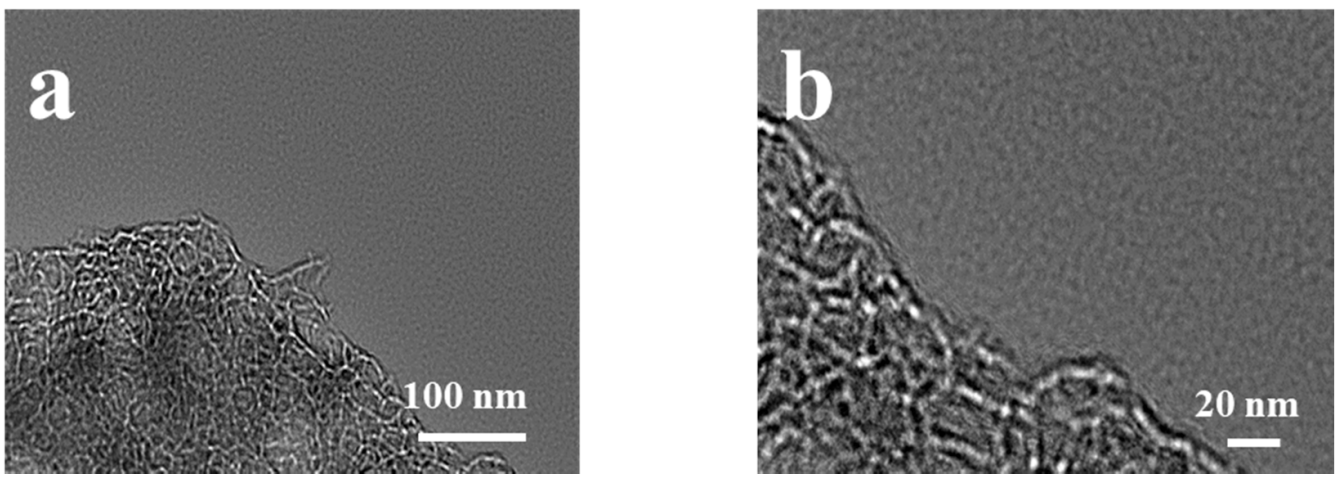

Figure 2. TEM images of TCZn-800 sample at (a) $100 \mathrm{~nm}$ and (b) $20 \mathrm{~nm}$. 
(a)

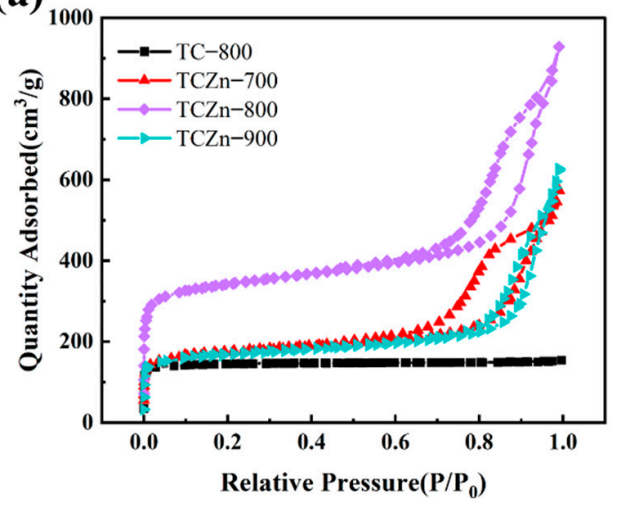

(b)

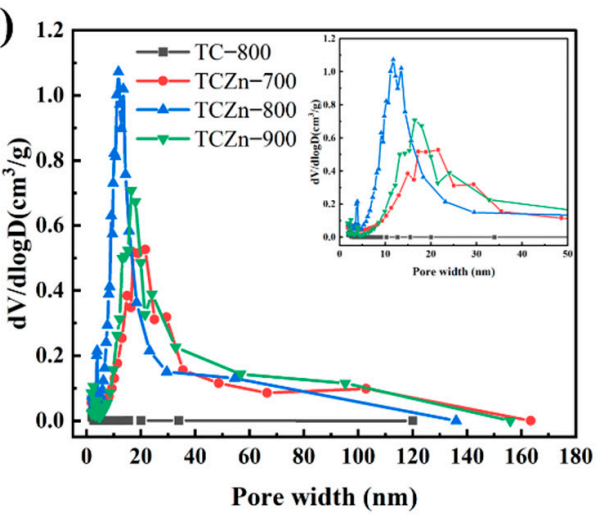

Figure 3. (a) $\mathrm{N}_{2}$ adsorption/desorption isotherms and (b) pore size distributions for all samples.

Table 1. Structural characteristics of the as-prepared materials.

\begin{tabular}{|c|c|c|c|c|}
\hline Samples & $\begin{array}{c}S_{B E T} \\
\left(\mathrm{~m}^{2} \cdot \mathrm{g}^{-1}\right)\end{array}$ & $\begin{array}{c}S_{\text {micro }} \\
\left(\mathrm{m}^{2} \cdot \mathrm{g}^{-1}\right)\end{array}$ & $\begin{array}{c}V_{\text {total }} \\
\left(\mathrm{cm}^{3} \cdot \mathrm{g}^{-1}\right)\end{array}$ & $\begin{array}{c}D_{a p} \\
(\mathrm{~nm})\end{array}$ \\
\hline TC-800 & 569.4 & 557.7 & 0.23 & 1.67 \\
\hline TCZn-700 & 650.4 & 503.4 & 0.88 & 5.41 \\
\hline TCZn-800 & 1293.2 & 1057.0 & 1.43 & 4.43 \\
\hline TCZn-900 & 625.4 & 498.0 & 0.96 & 6.17 \\
\hline
\end{tabular}

$S_{B E T}$ : specific surface area; $S_{\text {micro }}$ : micropore surface area; $V_{\text {total }}$ : pore volume; $D_{a p}$ : average pore diameter.

The crystalline structures of all the TCZn-X samples were further analyzed using XRD and Raman spectroscopy. As shown in Figure 4a, all the samples show a similar XRD pattern, and there are two broad diffraction peaks centered at $26^{\circ}$ and $44^{\circ}$, just like most other reported biomass-derived charcoal $[42,43]$. These peaks correspond to the $(002)$ and (110) planes of graphite, suggesting the amorphous carbon [44]. The Raman spectra (Figure $4 \mathrm{~b}$ ) of all the TCZn-X samples display two characteristic peaks; one is D peak at the $1335 \mathrm{~cm}^{-1}$, and the other is $G$ peak at the $1590 \mathrm{~cm}^{-1}$, which are typical peaks of the carbon materials. The $\mathrm{D}$ and $\mathrm{G}$ peaks are related to disordered carbon structure and graphitic lattice, respectively. In general, the intensity ratio of the $D$ and $G$ band $\left(I_{D} / I_{G}\right)$ is used to indicate the degree of graphitization $[45,46]$. The $\mathrm{I}_{\mathrm{D}} / \mathrm{I}_{\mathrm{G}}$ values of TCZn-700, TCZn-800 and TCZn-900 are 1.12, 1.31, and 1.24, respectively. Significantly, the $\mathrm{I}_{\mathrm{D}} / \mathrm{I}_{\mathrm{G}}$ value of TCZn-800 is the highest of all the samples. Meanwhile, the higher the $\mathrm{I}_{\mathrm{D}} / \mathrm{I}_{\mathrm{G}}$ value is, the higher the graphitization degree of carbon material is, and the higher the conductivity of TCZn-X as electrode material is [47]. Therefore, the graphitization degree and the conductivity of TCZn- 800 was all the highest, which is probably due to the proper temperature, promoting the activation and templating effect of nano- $\mathrm{ZnO}$, which would result in a large number of defects.

(a)

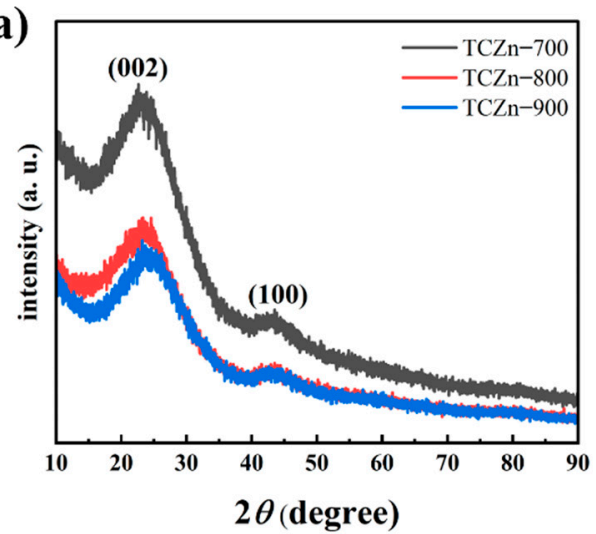

(b)

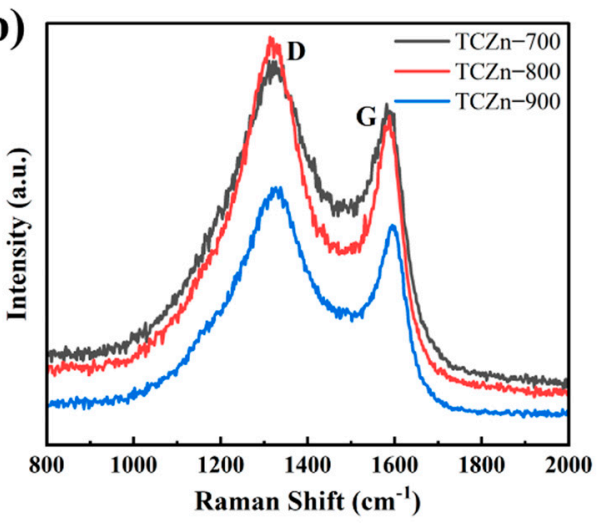

Figure 4. (a) XRD patterns and (b) Raman spectra of TCZn-700, TCZn-800 and TCZn-900. 


\subsection{Electrochemical Characterization}

The electrochemical performances of all the samples were carried out using a threeelectrode configureuration in $6 \mathrm{M} \mathrm{KOH}$ aqueous solution electrolyte (Figures 5 and 6). The $\mathrm{CV}$ curve reflects the ions adsorption of the electrode material, which is related to the charge storage mechanism of EDCL. As shown in Figure 5a, the CV curves of TCZn-700, TCZn-800 and TCZn-900 exhibit rectangular shape at $10 \mathrm{mV} \cdot \mathrm{s}^{-1}$ scan rate with a voltage range of -1 to $0 \mathrm{~V}$, indicating their superior double-layer capacitor behavior. Unlike the other three samples, the CV curve of TC-800 showed a distorted rectangular shape, suggesting a poor EDLC performance. This could be attributed to the ion-sieve effect of samples, which was caused by the lack of mesoporous. The area bounded by the CV curve of the TCZn-800 is distinctly larger than others, demonstrating its best specific capacitance, which is consistent with the TEM and BET results. In addition, under different carbonization temperatures, the $\mathrm{CV}$ enclosed areas of the TCZn- $\mathrm{X}$ are quite different, indicating that their capacitances are different. It can be seen that when the temperature increasing, the area of the $\mathrm{CV}$ curve becomes larger, but when the temperature reached $900{ }^{\circ} \mathrm{C}$, the area of the $\mathrm{CV}$ curve decreased. This is mainly because the low-temperature annealed sample (TCZn-700) was insufficient carbonization, which resulted to a weak electronic conductivity and small specific surface area. While the sample was annealed at an excessive hightemperature (TCZn-900), excessive carbonization leads to large pore size, limited specific surface area and high crystallinity. Generally, the larger area of the CV curve, the higher of capacitance, and the stronger adsorption capacity of EDCL for ions [48,49]. So, the carbonization temperature is one of the important factors affecting the performance of biochar materials. The GCD curves of all the samples show an isosceles triangle shape at $1 \mathrm{~A} \cdot \mathrm{g}^{-1}$ current density (Figure $5 \mathrm{~b}$ ). This phenomenon indicated that all the samples own a favorable reversibility of electrochemical and high coulombic efficiency. Notably, all the TCZn-X show a much longer discharge time than TC-800. Specifically, TCZn-800 showed the longest discharge time, which reflects its advantage of high SSA and pore structure for capacitance improvement. The excellent electrochemical performance of the TCZn-800 sample could be attributed to the activation and templating of nano- $\mathrm{ZnO}$ and appropriate carbonization-activation temperature [50].

Figure $5 \mathrm{c}$ summarized the rate capability of all samples under different densities as derived from their GCD curves. It is further verified that porous structure and high specific surface area are helpful in enhancing the TCZn- $X^{\prime}$ 's specific capacitance. The specific capacitance of TC-800, TCZn-700, TCZn-800 and TCZn-900 were 128.7, 179.2, 220.7 and $136.7 \mathrm{~F} \cdot \mathrm{g}^{-1}$ at $1 \mathrm{~A} \cdot \mathrm{g}^{-1}$ current density. But when the current density is up to $10 \mathrm{~A} \cdot \mathrm{g}^{-1}$, the specific capacitances were $93.4,149.8,186.9$ and $115.2 \mathrm{~F} \cdot \mathrm{g}^{-1}$, respectively. Obviously, TCZn-800 sample shows the highest specific capacitance; the specific capacitance retention is $84.69 \%$ from $1 \mathrm{~A} \cdot \mathrm{g}^{-1}$ to $10 \mathrm{~A} \cdot \mathrm{g}^{-1}$ current density. Figure 6 shows CV curves and GCD curves of TCZn-800 at different scan rates and current densities to further investigate its electrochemical performance. Its CV curve still maintained a quasi-rectangular outline at a high scan rate (Figure 6a); the GCD curves also exhibited typical electrochemical capacitor behavior over a wide range of current densities (Figure 6b), suggesting its excellent capacitive behavior.

The electrochemical impedance spectroscopy (EIS) was carried out over the frequency range from $0.01 \mathrm{~Hz}$ to $100 \mathrm{kHz}$ to further explore the electrochemical properties of TCZn-X samples. Figure $5 \mathrm{~d}$ displays the Nyquist plots of all samples, which can be divided in two distinct parts, the low frequency $\left(R_{s}\right)$ and the high frequency $\left(R_{c t}\right.$ : charge transfer resistance), respectively [51]. At low frequency, the more vertical the plots slope, the faster the diffusion of ions, which would result in a higher conduction performance [52]. So, the ionic diffusion capacity of all the samples is faster. Moreover, the $\mathrm{R}_{\mathrm{ct}}$ values of all the samples are fairly low, suggesting good conductivity. 
(a) 1.5

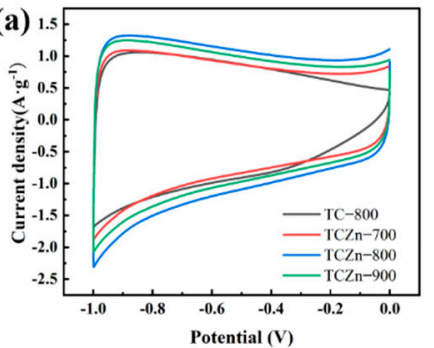

(c)

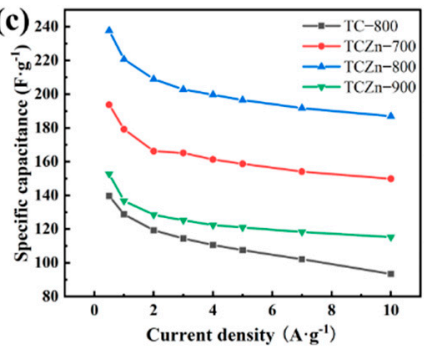

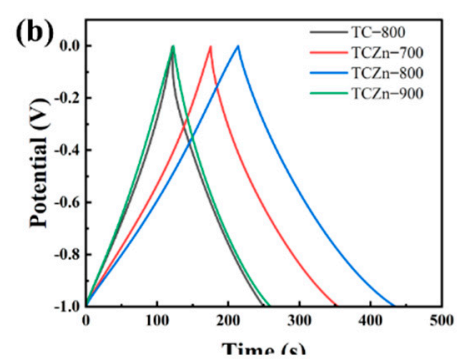

(d)

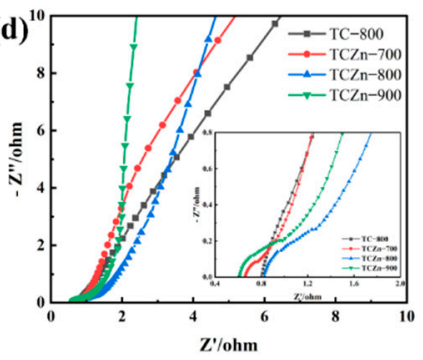

Figure 5. Electrochemical properties of all samples (a) CV curves at $10 \mathrm{mV} \cdot \mathrm{s}^{-1}$; (b) GCD curves at $1 \mathrm{~A} \cdot \mathrm{g}^{-1} ;$ (c) Specific capacitance at different current densities and (d) Nyquist plots.

(a)

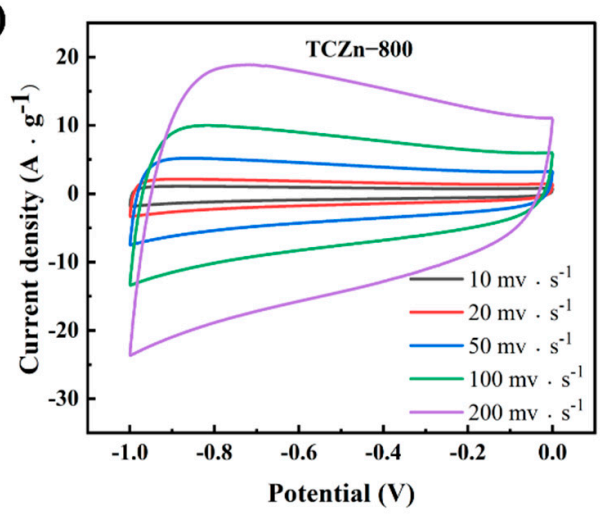

(b)

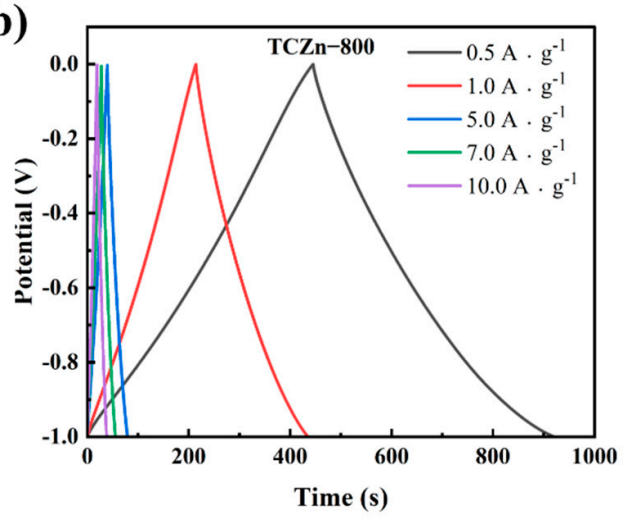

Figure 6. (a) CV curves at different scan rates and (b) GCD curves at different current densities of TCZn-800.

To further check the long cycle life of TCZn-800, it was tested under a current density of $5 \mathrm{~A} \cdot \mathrm{g}^{-1}$. As shown in Figure 7, the GCD curves of the first few cycles and the last few cycles are almost isosceles triangles, and the capacitance retention is about $94.83 \%$ after 3000 cycles. These above results confirm the excellent cycle stability of TCZn- 800 .
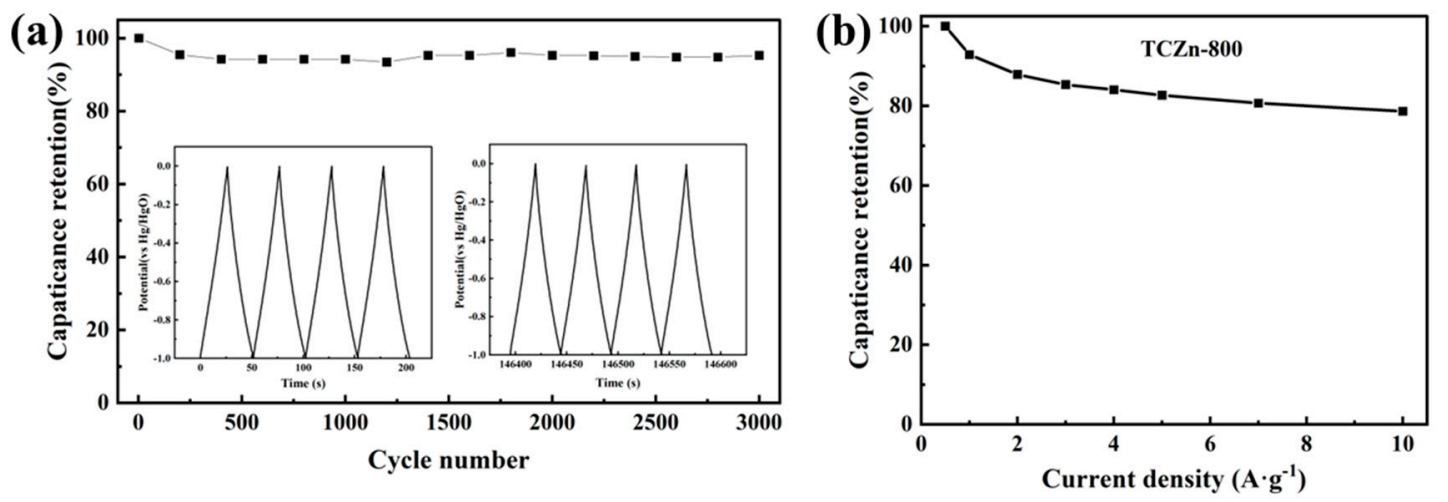

Figure 7. (a) 3000-cycle stability test at $5 \mathrm{~A} \cdot \mathrm{g}^{-1}$ and (b) the capacitance retention with different current densities of TCZn-800. 


\section{Conclusions}

With tobacco straw as a carbon source and nano- $\mathrm{ZnO}$ as a hard template and activator, tobacco straw-derived porous activated carbon was successfully prepared by one-step carbonization activation method and ball milling method. The results show that different carbonization temperatures have a profound effect on the surface morphology of bioporous carbon materials, and then affect their electrochemical performance. When the carbonization temperature was $800^{\circ} \mathrm{C}$, the biochar (TCZn-800) had a high specific surface area $\left(1293.2 \mathrm{~m}^{2} \cdot \mathrm{g}^{-1}\right)$ and mesoporous structure. TCZn-800 exhibits superior performance with a capacitance of $220.7 \mathrm{~F} \cdot \mathrm{g}^{-1}$ at $1 \mathrm{~A} \cdot \mathrm{g}^{-1}$ in a three-electrode configureuration and excellent cycle life (about $94.83 \%$ capacitance at $5 \mathrm{~A} \cdot \mathrm{g}^{-1}$ after 3000 cycles). This work displays a simple method for preparing excellent-performance porous carbon electrode using biomass-straw and provides ideas for the resource utilizations of waste tobacco straws and other biomass resources.

Author Contributions: Conceptualization, B.J., L.C., Q.Y., Z.M., Z.H., Z.L. and P.Z.; methodology, Z.L., P.Z., L.C. and B.J.; formal analysis, Q.Y. and Z.H.; investigation, L.C., Z.M. and Z.H.; resources, Z.L., P.Z. and L.C.; data curation, B.J., L.C. and Q.Y.; writing-original draft preparation, B.J. and P.Z.; writing—review and editing, all authors.; visualization, Q.Y., Z.M. and Z.H.; supervision, Z.L., P.Z. and L.C.; project administration, Z.L., P.Z. and L.C.; funding acquisition, Z.L., P.Z. and L.C. All authors have read and agreed to the published version of the manuscript.

Funding: This research was supported by the Scientific Cultivation and Innovation Fund Project of Jinan University (no. 21621414 and 21621111), the National Natural Science Foundation of China (no.51801065) and Guangdong Science and Technology Project (no. 2021A1515012271 and 2019011).

Institutional Review Board Statement: Not applicable.

Informed Consent Statement: Not applicable.

Data Availability Statement: The data presented in this study are available on request from the corresponding author.

Conflicts of Interest: The authors declare no conflict of interest.

\section{References}

1. Yang, D.P.; Li, Z.B.; Liu, M.H.; Zhang, X.Y.; Chen, Y.S.; Xue, H.; Ye, E.Y.; Luque, R. Biomass-Derived Carbonaceous Materials: Recent Progress in Synthetic Approaches, Advantages, and Applications. Sustain. Chem. Eng. 2019, 7, 4564-4585. [CrossRef]

2. Appavou, F.; Brown, A.; Epp, B.; Gibb, D.; Kondev, B.; McCrone, A.; Murdock, H.E.; Musolino, E.; Ranalder, L.; Sawin, J.L.; et al. Renewables 2019 Global Status Report; Renewable Energy Policy Network for the 21st Century, Paris, French. 2019. Available online: http://www.ren21.net/wp-content/uploads/2019/05/gsr2019_full_report_en.pdf (accessed on 9 April 2020).

3. Wang, C.; Wang, W.; Dang, B.K.; Wang, Z.; Shen, P.; Li, C.C.; Sun, Q.F. Ultrahigh yield of nitrogen doped porous carbon from biomass waste for supercapacitor. Renew. Energy 2020, 156, 370-376.

4. China Statistical Yearbook 2019. Available online: http://www.stats.gov.cn/tjsj/ndsj/2019/indexeh.htm (accessed on 6 August 2020).

5. Liu, Z.; Xu, A.; Long, B. Energy from combustion of rice straw: Status and challenges to China. Energy Power Eng. 2011, 3, 325-331. [CrossRef]

6. Cui, M.; Zhao, L.X.; Tian, Y.S.; Meng, H.B.; Sun, L.Y.; Zhang, Y.L.; Wang, F.; Lin, B.F. Analysis and evaluation on energy utilization of main crop straw resources in China. Trans. Chin. Soc. Agric. Eng. 2008, 24, 291-296.

7. Fang, C.; Hu, P.; Dong, S.; Cheng, Y.; Zhang, D.Y.; Zhang, X.H. Construction of carbon nanorods supported hydrothermal carbon and carbon fiber from waste biomass straw for high strength supercapacitor. J. Colloid Interface Sci. 2021, 582, 552-560. [CrossRef]

8. Huang, Z.R.; Qin, C.Y.; Wang, J.; Cao, L.; Ma, Z.W.; Yuan, Q.H.; Lin, Z.D.; Zhang, P. Research on High-Value Utilization of Carbon Derived from Tobacco Waste in Supercapacitors. Materials 2021, 14, 1714. [CrossRef] [PubMed]

9. Seglah, P.A.; Wang, Y.J.; Wang, H.Y.; Bi, Y.Y.; Zhou, K.; Wang, Y.; Wang, H.; Feng, X.X. Crop straw utilization and field burning in Northern region of Ghana. J. Clean. Prod. 2020, 261, 121191. [CrossRef]

10. Jeyasubramanian, K.; Thangagiri, B.; Sakthivel, A.; Raja, J.D.; Seenviasan, S.; Vallinayagam, P.; Madhavan, D.; Devi, S.M.; Rathika, B. A complete review on biochar: Production, property, multifaceted applications, interaction mechanism and computational approach. Fuel 2021, 292, 120243. [CrossRef]

11. Zhang, Y.Y.; Gao, Z.; Song, N.N.; Li, X.D. High-performance supercapacitors and batteries derived from activated banana-peel with porous structures. Electrochim. Acta. 2016, 222, 1257-1266. [CrossRef]

12. Xue, M.Z.; Lu, W.Z.; Chen, C. Optimized synthesis of banana peel derived porous carbon and its application in lithium sulfur batteries. Mater. Res. Bull. 2019, 112, 269-280. [CrossRef] 
13. Xu, M.M.; Huang, Q.B.; Lu, J.J.; Niu, J.F. Green synthesis of high-performance supercapacitor electrode materials from agricultural corncob waste by mild potassium hydroxide soaking and a one-step carbonization. Ind. Crops Prod. 2021, 161, 113215. [CrossRef]

14. Mohammend, A.A.; Chen, C.; Zhu, Z.H. Low-cost, high-performance supercapacitor based on activated carbon electrode materials derived from baobab fruit shells. J. Colloid Interface Sci. 2019, 538, 308-319. [CrossRef] [PubMed]

15. Qin, F.R.; Zhang, K.; Li, J.; Lai, Y.Q.; Lu, H.; Yu, F.; Lei, X.K.; Fang, J. Pomegranate rind-derived activated carbon as electrode material for high-performance supercapacitors. J. Solid State Electrochem. 2016, 20, 469-477. [CrossRef]

16. Liu, W.; Mei, J.; Liu, G.L.; Kou, Q.; Yi, T.F.; Xiao, S.J. Nitrogen-Doped Hierarchical Porous Carbon from Wheat Straw for Supercapacitors. ACS Sustain. Chem. Eng. 2018, 6, 11595-11605. [CrossRef]

17. Wang, L.W.; Ok, Y.S.; Tsang, D.C.W.; Alessi, D.S.; Rinklebe, J.; Wang, H.J.; Masek, O.; Hou, R.J.; O'Connor, D.; Hou, D.Y. New trends in biochar pyrolysis and modification strategies: Feedstock, pyrolysis conditions, sustainability concerns and implications for soil amendment. Soil Use Manag. 2020, 36, 358-386. [CrossRef]

18. Palansooriya, K.N.; Yang, Y.; Tsang, Y.F.; Sarkar, B.; Hou, D.; Cao, X.D.; Meers, E.; Rinklebe, J.; Kim, K.H.; Ok, Y.S. Occurrence of contaminants in drinking water sources and the potential of biochar for water quality improvement: A review. Crit. Rev. Environ. Sci. Technol. 2019, 50, 549-611. [CrossRef]

19. Kumar, A.; Saini, K.; Bhaskar, T. Advances in design strategies for preparation of biochar based catalytic system for production of high value chemicals. Bioresour. Technol. 2020, 299, 122564. [CrossRef]

20. Gao, Z.; Zhang, Y.; Song, N.; Li, X. Biomass-derived renewable carbon materials for electrochemical energy storage. Mater. Res. Lett. 2017, 5, 69-88. [CrossRef]

21. Le, T.H.; Ngo, V.H.; Nguyen, M.T.; Nguyen, V.C.; Vu, D.N.; Pham, T.D.; Tran, D.T. Enhanced Electrochemical Performance of Porous Carbon Derived from Cornstalks for Supercapacitor Applications. J. Electron. Mater. 2021, 50, 6854-6861. [CrossRef]

22. Zhao, Y.Q.; Lu, M.; Tao, P.Y.; Zhang, Y.J.; Gong, X.T.; Yang, Z.; Zhang, G.Q.; Li, H.L. Hierarchically porous and heteroatom doped carbon derived from tobacco rods for supercapacitors. J. Power Sources 2016, 307, 391-400. [CrossRef]

23. Yuan, Q.H.; Ma, Z.W.; Chen, J.B.; Haung, Z.R.; Fang, Z.B.; Zhang, P.; Lin, Z.D.; Cui, J. N, S-Codoped Activated Carbon Material with Ultra-High Surface Area for High-Performance Supercapacitors. Polymers 2020, 12, 1982. [CrossRef]

24. Sun, W.; Lipka, S.M.; Swartz, C.; Williams, D.; Yang, F. Hemp-derived activated carbons for supercapacitors. Carbon 2016, 103, 181-192. [CrossRef]

25. Wu, C.; Yang, S.R.; Cai, J.J.; Zhang, Q.B.; Zhu, Y.; Zhang, K.L. Activated microporous carbon derived from almond shell for high energy density asymmetric supercapacitors. ACS Appl. Mater. Interfaces 2016, 8, 15288-15296. [CrossRef]

26. Cui, Y.H.; Zhang, Q.; Wu, J.W.; Liang, X.; Baker, A.P.; Qu, D.Y.; Zhang, H.Y.; Zhang, X.H. Developing porous carbon with dihydrogen phosphate groups as sulfur host for high performance lithium sulfur batteries. Power Sources 2018, 378, 40-47. [CrossRef]

27. Zhang, J.M.; Hua, Q.S.; Li, J.; Yuan, J.S.; Peijs, T.; Dai, Z.Q.; Zhang, Y.S.; Zheng, Z.M.; Zheng, L.L.; Tang, J. Cellulose-derived highly porous three-dimensional activated carbons for supercapacitors. ACS Omega 2018, 3, 14933-14941. [CrossRef]

28. Liu, X.G.; Ma, C.D.; Li, J.X.; Zielinska, B.; Kalenczuk, R.J.; Chen, X.C.; Chu, P.K.; Tang, T.; Mijowska, E. Biomass-derived robust three-dimensional porous carbon for high volumetric performance supercapacitors. Power Sources 2019, 412, 1-9. [CrossRef]

29. Burleigh, M.C.; Markowitz, M.A.; Wong, E.M.; Lin, J.S.; Gaber, B.P. Synthesis of periodic mesoporous organosilicas with block copolymer templates. Chem. Mater. 2001, 13, 4411-4412. [CrossRef]

30. Hou, P.X.; Yamazaki, T.; Orikasa, H.; Kyotani, T. An easy method for the synthesis of ordered microporous carbons by the template technique. Carbon 2005, 43, 2624-2627. [CrossRef]

31. Gao, Y.; Zhang, Y.L.; Li, A.M.; Zhang, L. Facile synthesis of high-surface area mesoporous biochar for energy storage via in-situ template strategy. Mater. Lett. 2018, 230, 183-186. [CrossRef]

32. Gu, H.Y.; Cao, D.X.; Wang, J.K.; Lu, X.; Li, Z.H.; Niu, C.M.; Wang, H.K. Micro-CaCO 3 conformal template synthesis of hierarchical porous carbon bricks: As a host for $\mathrm{SnO}_{2}$ nanoparticles with superior lithium storage performance. Mater. Today Energy 2017, 4, 75-80. [CrossRef]

33. Chen, J.C.; Liu, Y.Q.; Li, W.J.; Yang, H.; Xu, L.Q. The large electrochemical capacitance of nitrogendoped mesoporous carbon derived from egg white by using a ZnO template. RSC Adv. 2015, 5, 98177-98183. [CrossRef]

34. Hsu, C.H.; Pan, Z.B.; Chen, C.R.; Wei, M.X.; Chen, C.A.; Lin, H.P.; Hsu, C.H. Synthesis of Multiporous Carbons from the Water Caltrop Shell for High-Performance Supercapacitors. ACS Omega 2020, 5, 10626-10632. [CrossRef]

35. Yu, F.; Ye, Z.H.; Chen, W.R.; Wang, Q.Y.; Wang, H.; Zhang, H.L.; Peng, C. Plane tree bark-derived mesopore-dominant hierarchical carbon for high-voltage supercapacitors. Appl. Surf. Sci. 2020, 507, 145190. [CrossRef]

36. Yu, S.K.; Wang, H.R.; Hu, C.; Zhu, Q.Z.; Qiao, N.; Xu, B. Facile synthesis of nitrogen-doped, hierarchical porous carbons with a high surface area: The activation effect of a nano-ZnO template. J. Mater. Chem. A. 2016, 4, 16341-16348. [CrossRef]

37. Qin, C.Y. Research on Resource Reuse of MF Resin/Tobacco Wastes in Supercapacitors. Master's Thesis, Jinan University, Guangzhou, China, 2021.

38. Vinayagam, M.; Babu, R.S.; Sivasamy, A.; Barros, A.L.F. Biomass-derived porous activated carbon from Syzygium cumini fruit shells and Chrysopogon zizanioides roots for high-energy density symmetric supercapacitors. Biomass Bioenergy 2020, $143,105838$. [CrossRef]

39. Hwang, B.; Yi, S.H.; Chun, S.E. Dual-role of $\mathrm{ZnO}$ as a templating and activating agent to derive porous carbon from polyvinylidene chloride (PVDC) resin. Chem. Eng. J. 2021, 442, 130047. [CrossRef] 
40. Yang, H.F.; Tang, Y.H.; Huang, X.G.; Wang, L.X.; Zhang, Q.T. Activated porous carbon derived from walnut shells with promising material properties for supercapacitors. J. Mater. Sci. Mater. Electron. 2017, 28, 18637-18645. [CrossRef]

41. Du, J.; Zhang, Y.; Lv, H.J.; Chen, A.B. Silicate-assisted activation of biomass towards N-doped porous carbon sheets for supercapacitors. J. Alloy. Compd. 2021, 853, 157091. [CrossRef]

42. Lu, B.H.; Zhou, J.; Song, Y.Q.; Wang, H.L.; Kiao, W.; Wang, D.H. Molten-salt treatment of waste biomass for preparation of carbon with enhanced capacitive properties and electrocatalytic activity towards oxygen reduction. Faraday Discuss. 2016, 190, 147-159. [CrossRef] [PubMed]

43. Wu, F.M.; Gao, J.P.; Zhai, X.G.; Xie, M.H.; Sun, Y.; Kang, H.Y.; Tian, Q.; Qiu, H.X. Hierarchical porous carbon microrods derived from albizia flowers for high performance supercapacitors. Carbon 2019, 147, 242-251. [CrossRef]

44. Ma, Y.Y.; Tian, J.Y.; Li, L.; Kong, L.T.; Liu, S.; Guo, K.K.; Chen, X.L. Interconnected hierarchical porous carbon synthesized from freeze-dried celery for supercapacitor with high performance. Int. J. Energy Res. 2021, 45, 9058-9068. [CrossRef]

45. Guo, N.N.; Li, M.; Wang, Y.; Sun, X.K.; Wang, F.; Yang, R. Soybean root-derived hierarchical porous carbon as electrode material for high-performance supercapacitors in ionic liquids. ACS Appl. Mater. Interface 2016, 8, 33626-33634. [CrossRef]

46. Zhao, C.J.; Ding, Y.W.; Huang, Y.X.; Li, N.; Hu, Y.Q.; Zhao, C.H. Soybean root-derived N, O co-doped hierarchical porous carbon for supercapacitors. Appl. Surf. Sci. 2021, 555, 149726. [CrossRef]

47. Ding, Y.; Li, Y.C.; Dai, Y.J.; Han, X.H.; Xing, B.; Zhu, L.J.; Qiu, K.Z.; Wang, S.R. A novel approach for preparing in-situ nitrogen doped carbon via pyrolysis of bean pulp for supercapacitors. Energy 2021, 216, 119227. [CrossRef]

48. Yang, S.H.; Song, X.F.; Zhang, P.; Gao, L.A. Crumpled nitrogen-doped graphene-ultrafine $\mathrm{Mn}_{3} \mathrm{O}_{4}$ nanohybrids and their application in supercapacitors. J. Mater. Chem. A 2013, 1, 14162-14169. [CrossRef]

49. Ai, J.G.; Yang, S.H.; Sun, Y.N.; Liu, M.; Zhang, L.; Zhao, D.G.; Wang, J.Q.; Yang, C.; Wang, X.T.; Cao, B.Q. Corncob cellulose-derived hierarchical porous carbon for high performance supercapacitors. J. Power Sources 2021, 484, 229221. [CrossRef]

50. Wang, L.; Hu, J.M.; Liu, J.X.; Xie, M.J.; Zhang, Y.; Chen, J.; Du, C.; Tian, Z.F. Heteroatom-doped porous carbons derived from lotus pollen for supercapacitors: Comparison of three activators. J. Alloy. Compd. 2021, 859, 158390.

51. Li, L.; Zhou, Y.M.; Zhou, H.; Qu, H.N.; Zhang, C.L.; Guo, M.X.; Liu, X.Q.; Zhang, Q.Y.; Gao, B. N/P Codoped Porous Carbon/OneDimensional Hollow Tubular Carbon Heterojunction from Biomass Inherent Structure for Supercapacitors. ACS Sustain. Chem. Eng. 2019, 7, 1337-1346. [CrossRef]

52. Chen, H.; Liu, D.; Shen, Z.H.; Bao, B.F.; Zhao, S.Y.; Wu, L.M. Functional Biomass Carbons with Hierarchical Porous Structure for Supercapacitor Electrode Materials. Electrochim. Acta. 2015, 180, 241-251. [CrossRef] 